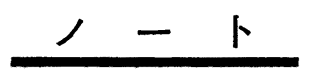

\title{
Structure of a Nekal-type Surfactant A-Commercial Twitchell Reagent "Idrapidspalter"—**1
}

\author{
Shunroku KANNO*, Akira SUZUKI**, Hajime BABA*, and Yasuo HANZAWA* \\ * Department of Applied Chemistry, Faculty of Engineering, Yamagata University \\ (3-16, Jōnan 4-chōme, Yonezawa-shi, Yamagata-ken) \\ ** Present address: Takemoto Oil \& Fat Co., Ltd. \\ (2-5, Minato-machi, Gamagōri-shi, Aichi-ken)
}

\begin{abstract}
The structure of a Nekal-type surfactant, which was prepared by sulfonation in the $\beta$-position of naphthalene followed by alkylation with isopropyl alcohol, was determined on the basis of an analysis on an NMR spectrum of its sulfonamide derivative. The pattern of the NMR spectrum observed in the lower magnetic field than $7 \mathrm{ppm}(\delta)$ showed characteristic substitutions of the alkyl and sulfonic acid groups on the naphthalene nucleus. From these results, this sulfonic acid was identified as 1,4-diisopropyl -6-naphthalene sulfonic acid.
\end{abstract}

From reasons based on their synthetic proces dures, the Nekal-type commercial surfactants have been usually considered as mixtures of various homologues and/or isomers of alkylnaphthalene= sulfonat $\mathrm{e}^{1)}$, and works on determining structures of these compounds were, with a few exception ${ }^{2}$, scarcely found within the limits of the authors' investigation. Marimon et al. ${ }^{3)}$ recently reported, on the basis of their chromatographical behavior, that technical samples of sodium propylnaphthale= nesulfonate were composed of several components with different degree of sulfonation and alkylation.

Previously, Kanno ${ }^{4}$ reported from the results of instrumental and elemental analyses on the potassium salt of the main component of "Idrapid = spalter"*2, a commercial Twitchell reagent, that this was identified as potassium diisopropyl= naphthalenemonosulfonate, and also that IR, UV, and NMR spectra, and X-ray diffraction pattern of this compound agreed with the corresponding properties of potassium diisopropylnaphthalene= $-\beta$-momosulfonate prepared by the procedure described by Lederer ${ }^{5}$.

With regard to the structure of the compound synthesized in such a way, Meyer et al. ${ }^{2)}$ estimated

*1 Presented in part at the Autumn Meeting on Coordi= nation Chemistry (Chūbu), October 16, 1973; Preprint, p. 177.

*2 Product of Deutsche Hydrierwerke A.G. (Düsseldorf) that the main component of this product was identified as sodium 1,6-diisopropylnaphthalene 3 (or 7)-sulfonate from the results of investigations on its several derivatives.

In the present paper, the authors confirmed that the structure of the fore-going diisopropyl naphthalene- $\beta$-mono sulfonic acid was represented as 1,4-diisopropylnaphthalene-6-sulfonic acid, on the basis of the NMR spectrum of the sulfon= amide derivative.

\section{Experimental}

\section{$1 \cdot 1$ Measurements}

The mp was uncorrected. The IR spectrum was recorded on a Hitachi EPI-S2 spectrometer ( $\mathrm{NaCl}$ prism). The NMR spectrum was deter= mined at $90 \mathrm{MHz}$ with a Hitachi R-22 High Resolution NMR spectrometer in deuterochloros form solution using tetramethylsilane as an internal standard. Their chemical shifts were presented in terms of $\delta$-values: s, singlet; d, doublet; $\mathrm{d}-\mathrm{d}$, double doublet; sept, septet.

\section{$1 \cdot 2$ Preparation of Potassium Diisopropyl naphthalene- $\boldsymbol{\beta}$-mono sulfonate}

Diisopropylnaphthalene- $\beta$-monosulfonic acid was prepared in accordance with the Lederer's procedure $^{5}$.

Naphthalene (192 g, $1.5 \mathrm{~mol}$ ) was sulfonatedin the $\beta$-position, in the usual way, with concen= 
trated sulfuric acid (192 $\mathrm{g}, 2 \mathrm{~mol})$ at $170 \sim 180^{\circ} \mathrm{C}$. After the sulfonation was over, the reaction mixture was diluted with concentrated sulfuric acid $(150 \mathrm{~g})$, and then a cooled mixture of isopropyl alcohol ( $189 \mathrm{~g}, 3.15 \mathrm{~mol}$ ) and concen= trated sulfuric acid $(300 \mathrm{~g}$ ) was added drop by drop into the sulfonated mixture at $120 \sim 130^{\circ} \mathrm{C}$ under refluxing and vigorous stirring. Alkylation was continued for $2 \mathrm{~h}$, then the reaction mixture was settled. After a separated sulfuric acid layer was removed, the reaction product was dissolved in diethyl ether, and then the ether solution was washed several times with $6 \mathrm{~N}$ sulfuric acid. The sulfonic acid dissolved in the ether solution was extracted with water, and subsequently neutralized with $25 \%$ potassium hydroxide aqueous solution. Potassium diisopropyl naphthalene- $\beta$-monosulfonate, colorless scales, was crystallized out from the aqueous solution, filtered off, and then recrystallized three times from water. Yield $59 \mathrm{~g}$ (13\% based on naphthalene, $30.7 \%$ for the crude potassium salt).

\subsection{Preparation of Diisopropylnaphthas lene- $\boldsymbol{\beta}$-mono sulfonic Acid}

An aqueous solution of barium chloride $(7.4 \mathrm{~g}$ $\mathrm{BaCl}_{2} \cdot 2 \mathrm{H}_{2} \mathrm{O} / 100 \mathrm{ml} \mathrm{H} \mathrm{H}_{2} \mathrm{O}$ ) was poured into a hot solution of the potassium salt $\left(2.0 \mathrm{~g} / 1000 \mathrm{ml} \mathrm{H}_{2} \mathrm{O}\right)$ under vigorous stirring. After the reaction mixture was cooled to room temperature, the precipitated barium sulfonate was filtered off, recrystallized twice from water, and then dried under reduced pressure. Yield $77 \%$, colorless needles.

The powdered barium sulfonate $(14 \mathrm{~g})$ was added to $1 \mathrm{~N}$ sulfuric acid $(70 \mathrm{ml})$, and the mixture was stirred for $1 \mathrm{~h}$ at $60^{\circ} \mathrm{C}$, and then produced barium sulfate was filtered off. The filtrate was made up to ca. $12 \mathrm{~N}$, on sulfuric acid, with concentrated sulfuric acid, and then the produced sulfonic acid was extracted with diethyl ether. After the ether was distilled off, recovered colorless crystals were recrystallized twice from a benzene-petroleum ether (bp 40 $\left.60^{\circ} \mathrm{C}\right)$ mixture $(1: 1, \mathrm{vol} / \mathrm{vol})$. Yield $50 \%$, colorless plate, $\mathrm{mp} 101 \sim 102^{\circ} \mathrm{C}$ (no lit.).

\section{$1 \cdot 4$ Preparation of Diisopropylnaphtha $=$ lene- $\boldsymbol{\beta}$-monosulfonamide}

The diisopropylnaphthalene- $\beta$-monosulfonic acid (2g) was heated at $95 \sim 98^{\circ} \mathrm{C}$ with phosphorpenta= chloride $(4 \mathrm{~g})$ on a water-bath. The reaction product was poured into water, then extracted with diethyl ether. The diisopropylnaphthalene= $-\beta$-monosulfonyl chloride, recovered from the ether solution, was converted to the sulfonamide by heating with ammonium carbonate $(2 \mathrm{~g})$. The produced sulfonamide was extracted with benzene, and then recrystallized from a benzene- $n$-hexane mixture $(1: 1, \mathrm{vol} / \mathrm{vol})$. Yield $72 \%$, colorless needles, mp $181.0 \sim 181.5^{\circ} \mathrm{C}$ (lit. $179 \sim 180^{\circ} \mathrm{C}^{2)}$ ). Found: C, 65.08\%; H, 7.63\% ; N, 4.78\%; mol. wt. (Rast), 296. Calcd. for $\mathrm{C}_{10} \mathrm{H}_{21} \mathrm{O}_{2} \mathrm{NS}: \mathrm{C}$, $65.95 \%$; H, 7.21\%; N, 4.81\% ; mol. wt. 291. IR spectrum $(\mathrm{KBr}$ disc $): \nu_{\mathrm{N}-\mathrm{H}} 3342$ and $3259 \mathrm{~cm}^{-1}$, $\nu_{\mathrm{S}=\mathrm{O}} 1300$ and $1172 \mathrm{~cm}^{-1}$. NMR (o, in $\mathrm{CDCl}_{3}$ ): $1.40 \mathrm{ppm}$ (isopropyl $\mathrm{CH}_{3}, 12 \mathrm{H}, \mathrm{d}, \mathrm{J}=7.0 \mathrm{~Hz}$ ), $3.76 \mathrm{ppm}$ (isopropyl $\mathrm{CH}, 2 \mathrm{H}$, sept, $\mathrm{J}=7.0 \mathrm{~Hz}$ ), $5.15 \mathrm{ppm}\left(\mathrm{NH}_{2}, 2 \mathrm{H}, \mathrm{s}\right), 7.50 \mathrm{ppm}$ (arom $\mathrm{H}, 2$ $\mathrm{H}, \mathrm{s}$ ), $7.90 \mathrm{ppm}$ (arom $\mathrm{H}, 1 \mathrm{H}, \mathrm{d}-\mathrm{d}, \mathrm{J}=9.3$ and $2.0 \mathrm{~Hz}$ ) $8.25 \mathrm{ppm}$ (arom $\mathrm{H}, 1 \mathrm{H}, \mathrm{d}, \mathrm{J}=9.3 \mathrm{~Hz}$ ), and $8.78 \mathrm{ppm}$ (arom $\mathrm{H}, 1 \mathrm{H}, \mathrm{d}, \mathrm{J}=2.0 \mathrm{~Hz}$ ).

\section{Result and Discussion}

As melting ranges of the diisopropylnaphthas lene- $\beta$-monosulfonic acid, reproduced by way of the barium salt, and its sulfonamide were considerably narrow $\left(101 \sim 102\right.$ and $181.0 \sim 181.5^{\circ} \mathrm{C}$, respecs tively), the well-known fact, that the Nekaltype surfactants may be mixtures of several homologues and/or isomers, should be doubtful. This study was undertaken to determine the chemical structure of the fore-going diisopropyl naphthalene- $\beta$-monosulfonic acid by means of analyzing the NMR spectrum of the sulfonamide derivative.

The NMR spectrum (Fig. -1$)$ shows the pres= ence of isopropyl methyl (doublet $(\mathrm{J}=7.0 \mathrm{~Hz}$ ) at 1.35 and $1.42 \mathrm{ppm}, 12 \mathrm{H}$ ), isopropyl methine (septet $(\mathrm{J}=7.0 \mathrm{~Hz})$ at $3.5 \sim 4.0 \cdot \mathrm{ppm}, 2 \mathrm{H})$, amino group in the sulfonamide group (com= paratively broad singlet at $5.15 \mathrm{ppm}, 2 \mathrm{H}$ ), and

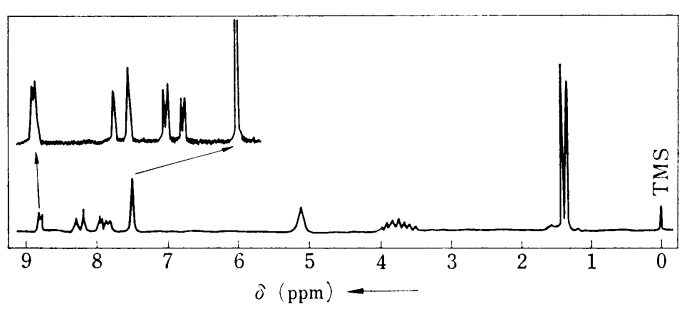

Fig.-1 The $90 \mathrm{MHz}$ NMR spectrum of the diisopropyl naphthalene- $\beta$-monosulfonamide, with sweep width $800 \mathrm{~Hz}$ and sweep time $200 \mathrm{~s}$ (in $\mathrm{CDCl}_{3}$ ). 
five ring-protons of naphthalene (lower magnetic field than $7 \mathrm{ppm}$ ).

Although, Meyer et $a l^{2}$. had offered such a structure as previously described on the sodium salt of this sulfonic acid, the pattern of the NMR spectrum presented in this paper was quitely different than that expected from the structure proposed by them.

As it is anticipated that the singlet peak at $7.50 \mathrm{ppm}$ is attributable to the presence of two structurally equivalent ring-protons, these protons should be attached to equivalent positions on the nucleus without the sulfonyl group. In this instance, it is reasonable to consider that each of the two isopropyl groups, introduced into the naphthalene nucleus following to the sulfonation, has to be substituted in the both $\alpha$-positions of the same nucleus, as is described in the Bord= well's work $^{6}$, because it seems, usually, to be difficult to substitute these groups in mutually adjacent $\beta$-positions of the nucleus, on the basis of their own steric effect.

From the results of these considerations and the following analyses on the NMR spectrum, this compound was reasonably identified as 1,4diisopropylnaphthalene-6-sulfonamide; that is,

(1) The structurally equivalent protons in the 2- and 3-positions were found as a singlet, corresponding to two protons, at $7.50 \mathrm{ppm}$ as described above. This peak was observed at the highest magnetic field in the ring-proton region, because these protons were in the $\beta$-positions of the naphthalene nucleus, and, moreover, were ad= jacent to the electron-releasing isopropyl groups ${ }^{7}$.

(2) The doublet $(\mathrm{J}=2.0 \mathrm{~Hz})$ at $8.78 \mathrm{ppm}$ were able to be assigned to the proton in the 5 -position, coupled with the meta-proton (7position), because these peaks appeared in the lowest magnetic field in this spectrum, as the result that the proton in this position joined at the $\alpha$-position of the nucleus, and, furthermore, was adjacent to the strongly electron-withdrawing sulfonyl group ${ }^{7}$.

(3) Peaks owing to the proton in the 7position were found at $7.90 \mathrm{ppm}$ as doubledoublet $(\mathrm{J}=9.3$ and $2.0 \mathrm{~Hz}$, respectively) ascrib= ed to couplings with the both ortho- and metaprotons (8- and 5-positions, respectively).

(4) The doublet $(\mathrm{J}=9.3 \mathrm{~Hz})$ at $8.25 \mathrm{ppm}$ were assigned to the proton in the 8-position coupled with the ortho-proton (7-position).

Consequently, it was recognized that the main component of the Nekal-type surfactant, prepared by means of the procedure described above, was identified as 1,4-diisopropylnaphthalene-6- sul= fonic acid and/or its salts.

(Received Sept. 3, 1976)

\section{References}

1) For example, A.M. Schwartz and J.W. Perry, "Surface Active Agents, Their Chemistry and Technology", Interscience Publishers, New York (1949) p. 116.

2) H. Meyer and K. Bernhauser, Monatsh. f. Chem., 53/54, 721 (1929).

3) J.M.O. Marimon and J.O.P. Calveras, "Berichte vom VI Internationalen Kongreß für grenzflächen -aktive Stoffe, Zürlich, Sept. 1972, Bd. I, Sek. A", Carl Hanser Verl., München (1973) p. 547.

4) S. Kanno, Kōgyō Kagaku Zasshi, 70, 1604 (1967).

5) H. Lederer, Melliand Textilber., 13, 540 (1932).

6) F.G. Bordwell, "Organic Chemistry", The Macs millan Co., New York (1963) p. 539.

7) J.W. Emsley, J. Feeney, and L.H. Sutcliffe, "High Resolution Nuclear Magnetic Resonance Spectroscopy, Vol. 2", Pergamon Press, New York (1966) p. 752. 